\title{
EVALUATION OF ANTIMICROBIAL POTENTIAL OF DIFFERENT SOLVENT EXTRACTS OF SOME MEDICINAL PLANTS OF SEMI-ARID REGION
}

\author{
HEMALI PADALIA, TEJAS RATHOD, SUMITRA CHANDA*
}

Department of Biosciences (UGC-CAS), Phytochemical, Pharmacological and Microbiological Laboratory, Saurashtra University, Rajkot, Gujarat, India. Email: svchanda@gmail.com

Received: 11 February 2017, Revised and Accepted: 01 August 2017

\section{ABSTRACT}

Objective: Infections caused by microorganisms that have become resistant to commonly used antibiotics have become a major nuisance globally. The problem of microbial resistance is increasing rapidly, and therefore there is an urgent need to develop novel antimicrobial agents from a natural source. The aim of the present study was to evaluate the antimicrobial activity of different solvent extracts of aerial part of Alysicarpus procumbens, Fimbristylis dichotoma, Saccharum spontaneum, Suaeda nigra, and Typha angustifolia against pathogenic microorganisms.

Methods: The extraction was done by individual cold percolation method using five solvents of different polarity, viz., petroleum ether, ethyl acetate, acetone, methanol, and water (aqueous). The antimicrobial activity was done by agar well diffusion method against Gram-positive and Gram-negative bacteria and fungi.

Results: All the plant solvent extracts showed varied level of antimicrobial activity against different microorganisms. All extracts of five plants showed better antibacterial activity than antifungal activity; Gram-positive bacteria were more susceptible than Gram-negative bacteria.

Conclusion: The polarity of solvent greatly influences extractive yield and antimicrobial activity of medicinal plants. The best activity was shown by solvent extracts of $S$. nigra. Hence, it can be considered as good source of antimicrobial agents.

Keywords: Medicinal plants, Antimicrobial activity, Extractive yield, Solvent extracts.

(C) 2017 The Authors. Published by Innovare Academic Sciences Pvt Ltd. This is an open access article under the CC BY license (http://creativecommons. org/licenses/by/4. 0/) DOI: http://dx.doi.org/10.22159/ajpcr.2017.v10i11.17662

\section{INTRODUCTION}

The use of plants as herbal medicine is widespread from ancient time. Even today in the times of advanced technology, medical science use plants for the treatment and curing of various diseases. The medicinal plants are considered as a rich source of bioactive phytochemicals which can be used in drug development [1]. Medicinal plants are frequently used for extraction of active constituents which are used in the preparation of different drugs [2]. Medicinal plants have been tested for a wide range of biological, activity such as antifungal [3], antioxidant [4], anti-inflammatory [5], hepatoprotective [6], antidiabetic [7], and anticancer [8] activities. Nowadays, the incidence of multiple drug resistance in pathogenic microorganisms is increasing largely. The number of multidrug resistant microbial strains and the appearance of strains with reduced susceptibility to antibiotics are continuously increasing [9]. This increase has been attributed to indiscriminate use of broad-spectrum antibiotics, immunosuppressive agent, intravenous catheters, organ transplantation, and ongoing epidemics of HIV infection $[10,11]$

Available synthetic drugs have side effects, adulteration and are also expensive and inadequate for the treatment of diseases. Therefore, there is need to search for a new infection fighting approach to control microbial infections [12]. This has lead to discover novel active compounds against resistance microbes with a novel mode of actions and new targets; this has become an urgent need. An attractive, advantageous and alternative approach is the use of medicinal plants. The plant based medicines are relatively safer than synthetic alternatives, very few side effects, high effectiveness, offering intense therapeutic benefits, and inexpensive treatment.

Plant produces a wide variety of secondary metabolites such as saponins, tannins, steroids, terpenoids, resins, and flavonoids which are used either directly as precursors or as lead compounds in the pharmaceutical industry. It is expected that plant extracts showing target sites other than those used by antibiotics will be active against drug resistant microbial pathogens. Bioactive compounds are normally accumulated as secondary metabolites in all plant cells, but their concentration varies according to the plant parts, season climate and particular growth phase [13]. Hence, in the present work five plants, viz., Alysicarpus procumbens, Fimbristylis dichotoma, Saccharum spontaneum, Suaeda nigra, and Typha angustifolia were selected to evaluate its antimicrobial potential against pathogenic microorganisms.

\section{METHODS}

Plant collection

Five plants were collected from Jamnagar and Surendranagar districts, Gujarat, India. The plant was compared with voucher specimen deposited at the Department of Biosciences, Saurashtra University, Rajkot, Gujarat, India. The aerial parts of five plants, i.e., A. procumbens Roxb. (AP) (Voucher Specimen No. PSN143), F. dichotoma L. (FD) (Voucher Specimen No. PSN772), S. spontaneum L. (SS) (Voucher Specimen No. PSN848), S. nigra L. (SN) (Voucher Specimen No. SU/ BIO/520/Thakrar), and T. angustifolia L (TA) (Voucher Specimen No. SU/BIO/522/Thakrar). They were thoroughly washed with tap water and dried under shade. The dried aerial parts were homogenized to a fine powder and stored in air tight bottles which were later used for solvent extraction.

\section{Extraction}

Individual cold percolation method

The dried powder of aerial parts of five plants was extracted individually by cold percolation method [14] using different organic solvents such as petroleum ether (PE), ethyl acetate (EA), acetone (AC), methanol (ME), 
and water (AQ). $10 \mathrm{~g}$ of dried powder was added to $100 \mathrm{ml}$ of PE in a conical flask, which was plugged with cotton wool and kept on a rotary shaker at $120 \mathrm{rpm}$ for $24 \mathrm{hrs}$. After $24 \mathrm{hrs}$, the extract was filtered with eight layers of muslin cloth and centrifuged at $5000 \mathrm{rpm}$ for 10 minutes. The supernatant was collected, and the solvent was evaporated. The residue was then added to $100 \mathrm{ml}$ of solvents (EA, acetone, methanol, and water) in different conical flasks, which were plugged with cotton wool and kept on a rotary shaker at $120 \mathrm{rpm}$ for $24 \mathrm{hrs}$. After $24 \mathrm{hrs}$, the extract was filtered with eight layers of muslin cloth and centrifuged at $5000 \mathrm{rpm}$ for 10 minutes. The supernatant was collected and the solvent was evaporated. The dry extract was stored at $4^{\circ} \mathrm{C}$ in airtight bottles; the extracts were weighed to obtain the extraction yield.

\section{Antimicrobial activity}

Antimicrobial activity was done by agar well diffusion method against Gram-positive bacteria, Gram-negative bacteria and fungal strains. The microorganisms were obtained from National Chemical Laboratory, Pune, India. The microorganisms were maintained at $4^{\circ} \mathrm{C}$. The bacteria and fungi were maintained on nutrient agar and MGYP medium (Hi Media, India), respectively. The Gram-positive bacteria studied were Bacillus cereus (BC) ATCC11778, Bacillus subtilis (BS) ATCC6633, Staphylococcus aureus (SA) ATCC29737, and Corynebacterium rubrum (CR) ATCC14898. The Gram-negative bacteria were Escherichia coli (EC) NCIM2931, Pseudomonas aeruginosa (PA) ATCC9027, Salmonella typhimurium (ST) ATCC23564, and Klebsiella pneumonia (KP) NCIM2719. The fungi studied were Candida albicans (CA) ATCC209l, Cryptococcus neoformans (CN) ATCC34664, Candida glabrata (CG) NCIM3448, and Candida epicola (CE) NCIM3367.

\section{Agar well diffusion assay}

In vitro antimicrobial activity of different extracts of $A$. procumbens, F. dichotoma, S. spontaneum, S. nigra, and T. angustifolia aerial parts were determined by agar well diffusion assay [15,16]. MuellerHinton agar and sabouraud dextrose agar were used for bacteria and fungi, respectively. Mueller Hinton agar and sabouraud dextrose agar $\left(40-42^{\circ} \mathrm{C}\right)$ were seed with $200 \mu \mathrm{l}$ of inoculums $(1 \times 108 \mathrm{cfu} / \mathrm{ml})$ and poured into Petri dishes. The media was allowed to solidify, and wells were prepared in the seeded agar plates with the help of a cup borer ( $8.5 \mathrm{~mm}$ ). Different solvent extracts were dissolved in $100 \%$ dimethyl sulfoxide (DMSO) at a concentration of $20 \mathrm{mg} / \mathrm{ml}$; from this $100 \mu \mathrm{l}$ of the extract was added into the $8.5 \mathrm{~mm}$ diameter well. The plates were incubated at $37^{\circ} \mathrm{C}$ and $28^{\circ} \mathrm{C}$ for 24 and $48 \mathrm{hrs}$ for bacteria and fungi, respectively. DMSO was used as a negative control. Antimicrobial activity was assayed by measuring the diameter of the zone of inhibition formed around the well in millimeters. The experiment was done in triplicate, and the average values are presented.

\section{RESULTS AND DISCUSSION}

\section{Extractive yield}

The extractive yield of different solvent extracts of aerial parts of five different plants is given in Fig. 1. The extractive yield was different in different solvent extracts of different plants. In all the five plants, maximum extractive yield was in methanol and aqueous extracts. The extractive yield was maximum in S. nigra and minimum in S. spontaneum. The extractive yield was minimum in PE, EA, and acetone extracts in all the five plants. The results support the idea that the solvent greatly affects the extractive yield, antimicrobial and antioxidant activity as also reported by Fernandez-Agullo et al., [17], Chanda et al., [18], Al-Farsi and Lee, [19] and Ammar et al., [20].

\section{Antimicrobial activity \\ Antimicrobial activity of A. procumbens}

Antimicrobial activity of different solvent extracts of A. procumbens against microorganisms is given in Fig. 2. Different solvent extracts showed a different level of activity against the tested microbial strains. All the extracts showed maximum antimicrobial activity toward Gram-positive bacteria as compared to Gram-negative bacteria and fungi. Gram-positive bacteria, B. cereus and B. subtilis were inhibited by all the five extracts. $S$. aureus was inhibited by semi polar solvent $E A$ and aqueous extract; while C. rubrum was inhibited by only semi polar solvent EA and polar solvent acetone extract (Fig. 2a). Gram-negative bacteria, E. coil, P. aeruginosa, S. typhimurium, and $K$. pneumoniae were not inhibited by any of the five solvent extracts (Fig. 2b). Fungi, C. epicola and C. glabrata were the most resistant fungal strains. C. albicans was inhibited by semi polar solvent EA and polar solvent acetone extracts. C. neoformans was inhibited by polar solvent acetone and methanol extracts and aqueous extracts (Fig. 2c). In general, EA and acetone extracts showed maximum antimicrobial activity. B. cereus and B. subtilis were the most susceptible bacterial strains.

\section{Antimicrobial activity of $\boldsymbol{F}$ dichotoma}

Antimicrobial activity of different solvent extracts of $F$. dichotoma against microorganisms is given in Fig. 3 . All the extracts showed moderate antimicrobial activity against microorganisms. The Grampositive bacteria, S. aureus was inhibited by semi polar solvent EA and polar solvent methanol extracts. B. subtilis and C. rubrum were inhibited by only polar solvent acetone extract. $B$. cereus was the most resistant bacterial strain (Fig. 3a). The Gram-negative bacteria, P. aeruginosa were inhibited by all the five extracts. E. coil was inhibited by non-polar solvent PE, semi polar solvent EA, polar solvent acetone, and methanol extracts. S. typhimurium and K. pneumoniae were the most resistant bacterial strains (Fig. 3b). Fungi, C. epicola and C. glabrata were the most resistant fungal strains. C. albicans was inhibited by all the

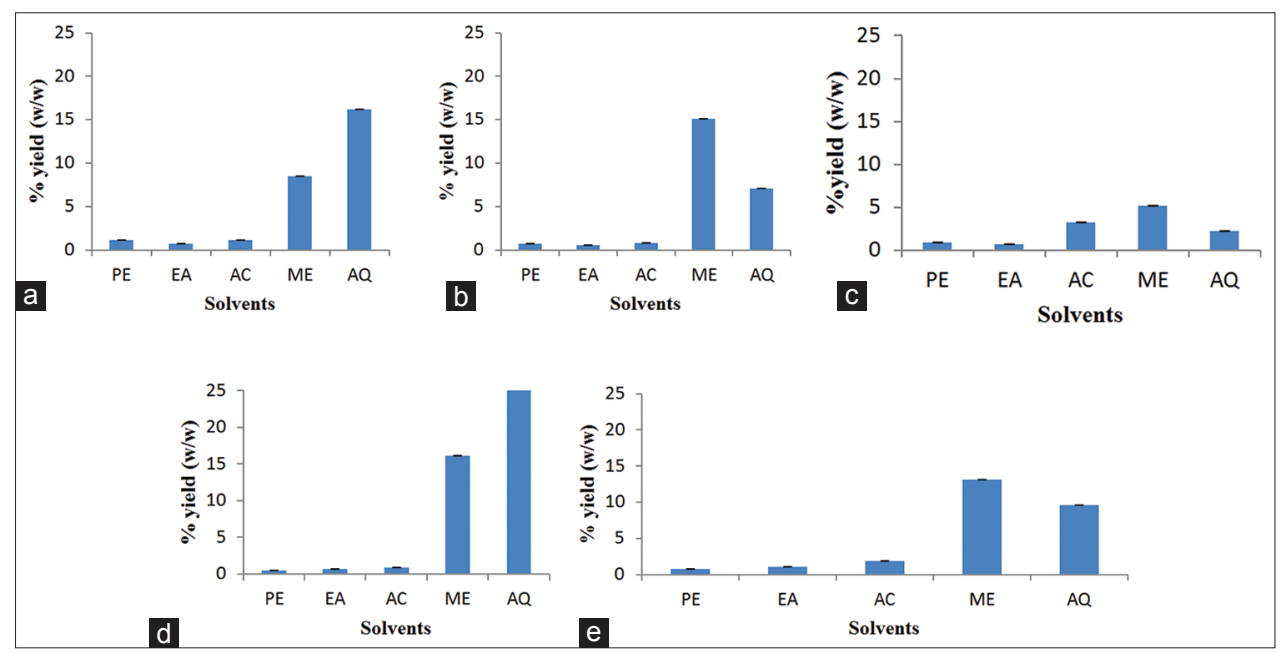

Fig. 1: Extractive yield of different solvent extracts of aerial part of plant (a) Alysicarpus procumbens, (b) Fimbristylis dichotoma, (c) Saccharum spontaneum, (d) Suaeda nigra, and (e) Typha angustifolia 


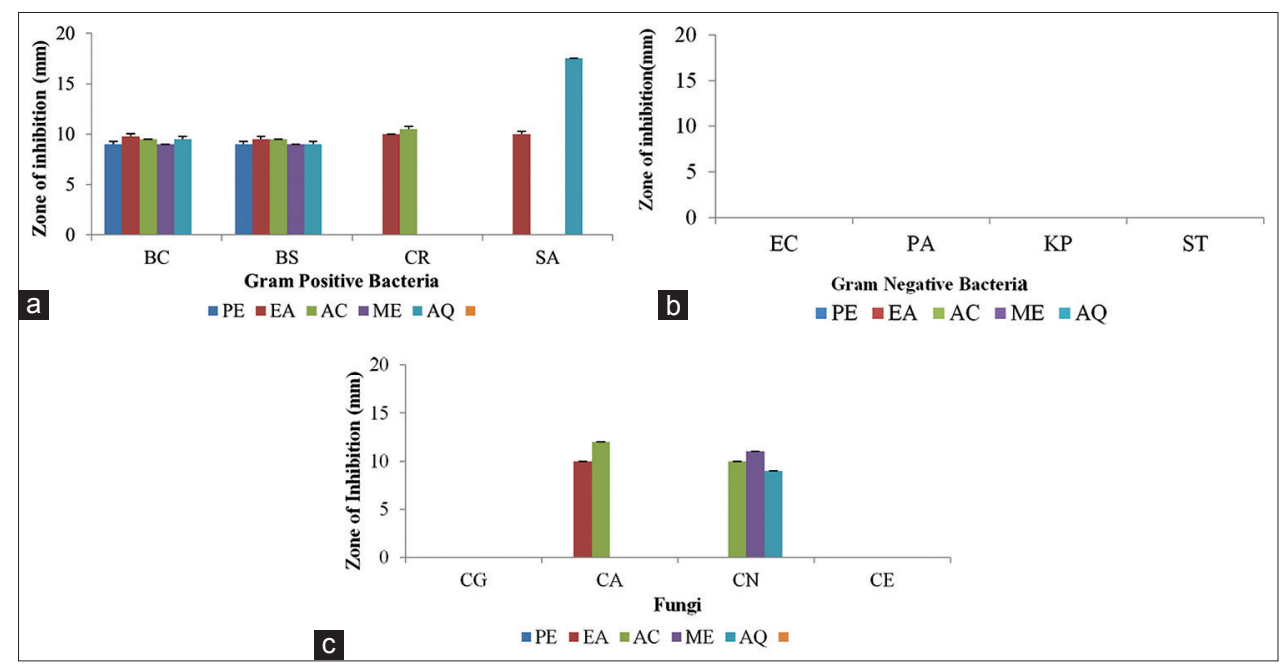

Fig. 2: Antimicrobial activity of different solvent extracts of $A$. procumbens against (a) Gram-positive bacteria, (b) Gram-negative bacteria, and (c) fungi

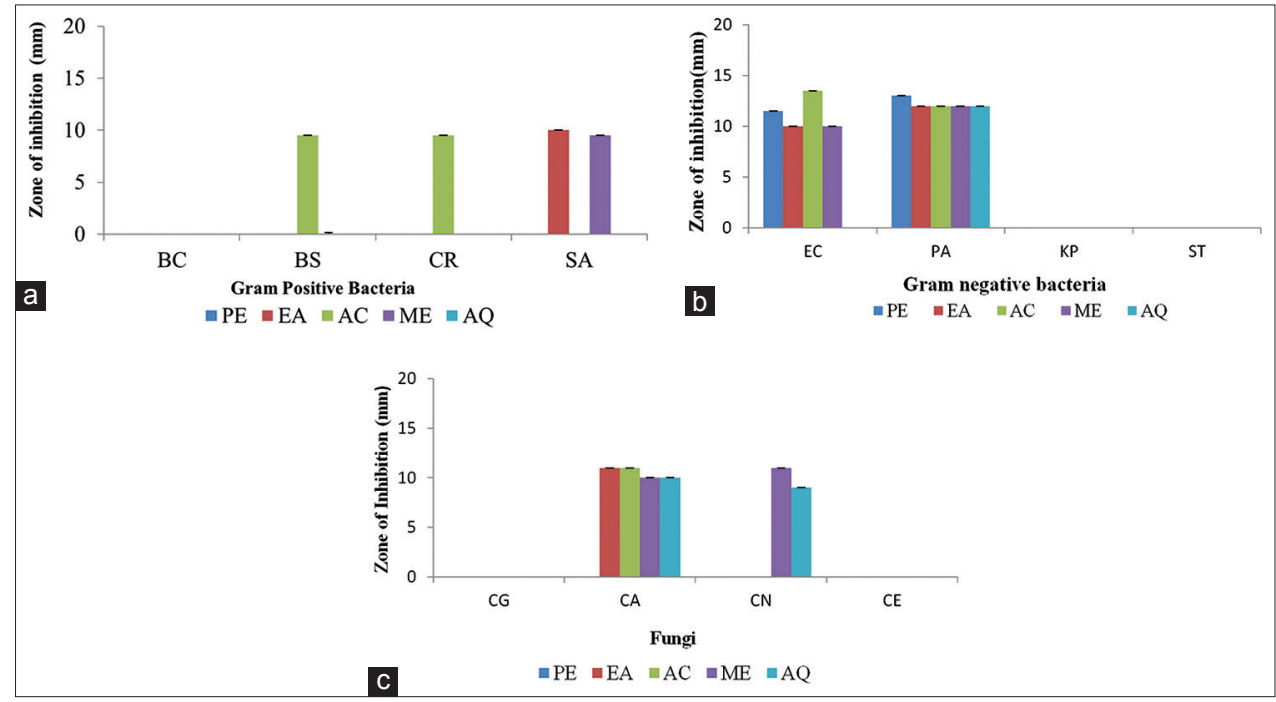

Fig. 3: Antimicrobial activity of different solvent extracts of $F$ dichotoma against (a) Gram-positive bacteria, (b) Gram-negative bacteria, and (c) fungi

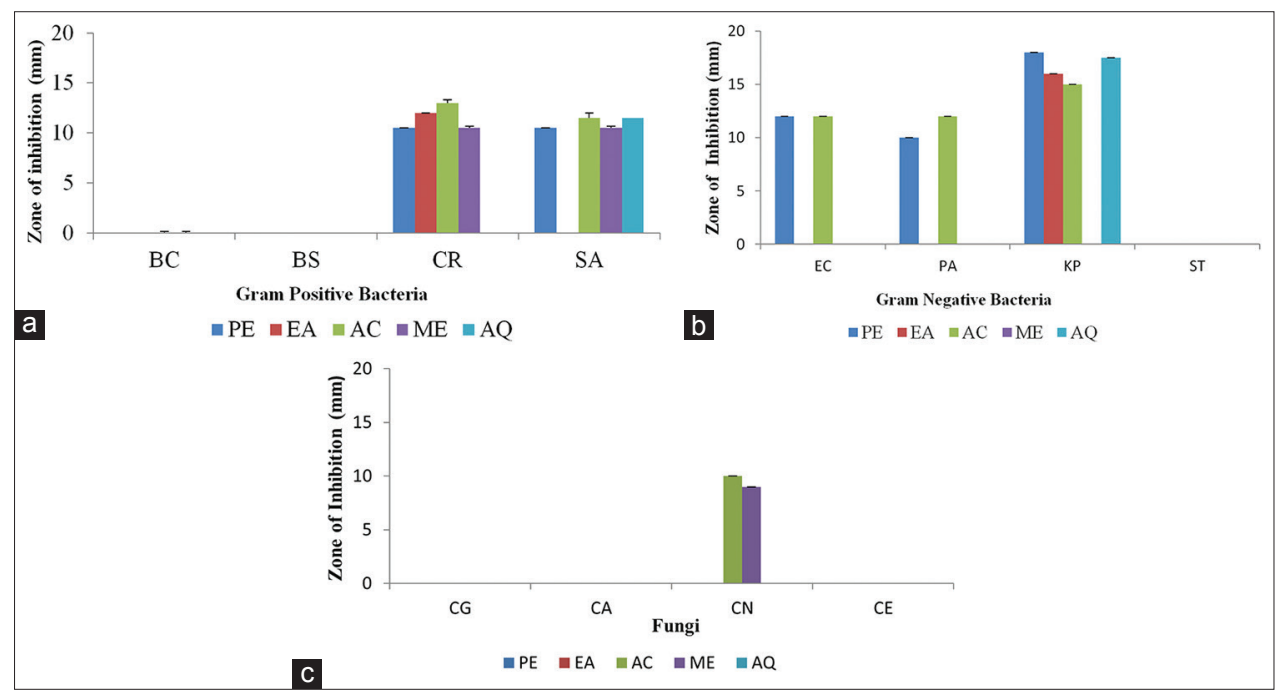

Fig. 4: Antimicrobial activity of different solvent extracts of $S$. spontaneum against (a) Gram-positive bacteria, (b) Gram-negative bacteria, and (c) fungi 
extracts except PE extract. C. neoformans was inhibited by polar solvent methanol and aqueous extracts (Fig. 3c). In general, methanol and acetone extracts showed maximum antimicrobial activity. P. aeruginosa was the most susceptible bacterial strain.

\section{Antimicrobial activity of $S$. spontaneum}

Antimicrobial activity of different solvent extracts of $S$. spontaneum aerial part against microorganisms is given in Fig. 4. All the extracts showed good antimicrobial activity toward Gram-positive bacteria and Gram-negative bacteria as compared to fungi. The Gram-positive bacteria, $C$. rubrum and $S$. aureus were inhibited by five extracts expect aqueous and EA, respectively. B. subtilis and B. cereus were the most resistant bacterial strain (Fig. 4a). The Gram-negative bacteria, $K$. pneumoniae, were inhibited by non-polar solvent $\mathrm{PE}$, semi polar solvent EA, polar solvent acetone, and aqueous extracts. P. aeruginosa and E. coil were inhibited by non-polar solvent PE and polar solvent acetone extracts. S. typhimurium was the most resistant bacterial strain (Fig. 4b). Fungi, C. epicola, C. albicans and C. glabrata were the most resistant fungal strain. C. neoformans was inhibited by polar solvent methanol and acetone extracts (Fig. 4c). In general, semi polar solvent PE extract and polar solvent acetone extract showed maximum antimicrobial activity. C. rubrum and S. aureus were the most susceptible bacterial strains.

\section{Antimicrobial activity of $S$. nigra}

Antimicrobial activity of different solvent extracts of $S$. nigra aerial part against microorganisms is given in Fig. 5. All the extracts showed moderate antimicrobial activity against the tested microorganisms. In Gram-positive bacteria, B. cereus was inhibited by five extracts expect aqueous extract. $S$. aureus was inhibited by Non Polar solvent PE extracts. B. subtilis and C. rubum were the most resistant bacteria strain (Fig. 5a). In Gram-negative bacteria, E. coil was inhibited by non-polar solvent PE, semi polar solvent EA, and polar solvent acetone extracts. P. aeruginosa was inhibited by non-polar solvent PE, semi polar solvent EA, and polar solvent methanol extracts. K. pneumoniae and S. typhimurium were the most resistant bacterial strains (Fig. 5b). Fungi, C. glabrata was inhibited by five extracts expect PE extract. $C$. albicans was inhibited by EA and methanol extracts. C. neoformans was inhibited by polar solvent acetone extract. C. epicola was the most resistant fungal strain (Fig. 5c). C. glabrata and B. cereus were the most susceptible bacterial strains.

\section{Antimicrobial activity of $T$. angustifolia}

Antimicrobial activity of different solvent extracts of T. angustifolia aerial part against microorganism is given in Fig. 6. All the extracts show good antimicrobial activity toward Gram-positive bacteria

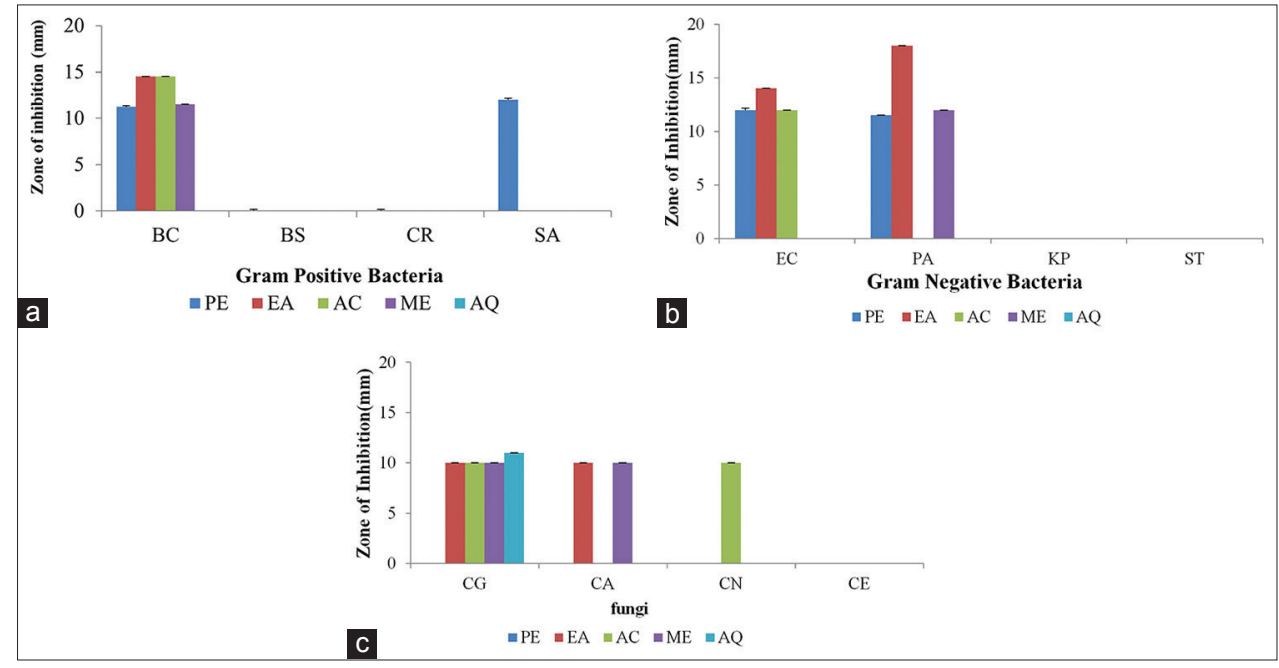

Fig. 5: Antimicrobial activity of different solvent extracts of Suaeda nigra against (a) Gram-positive bacteria, (b) Gram-negative bacteria, and (c) fungi

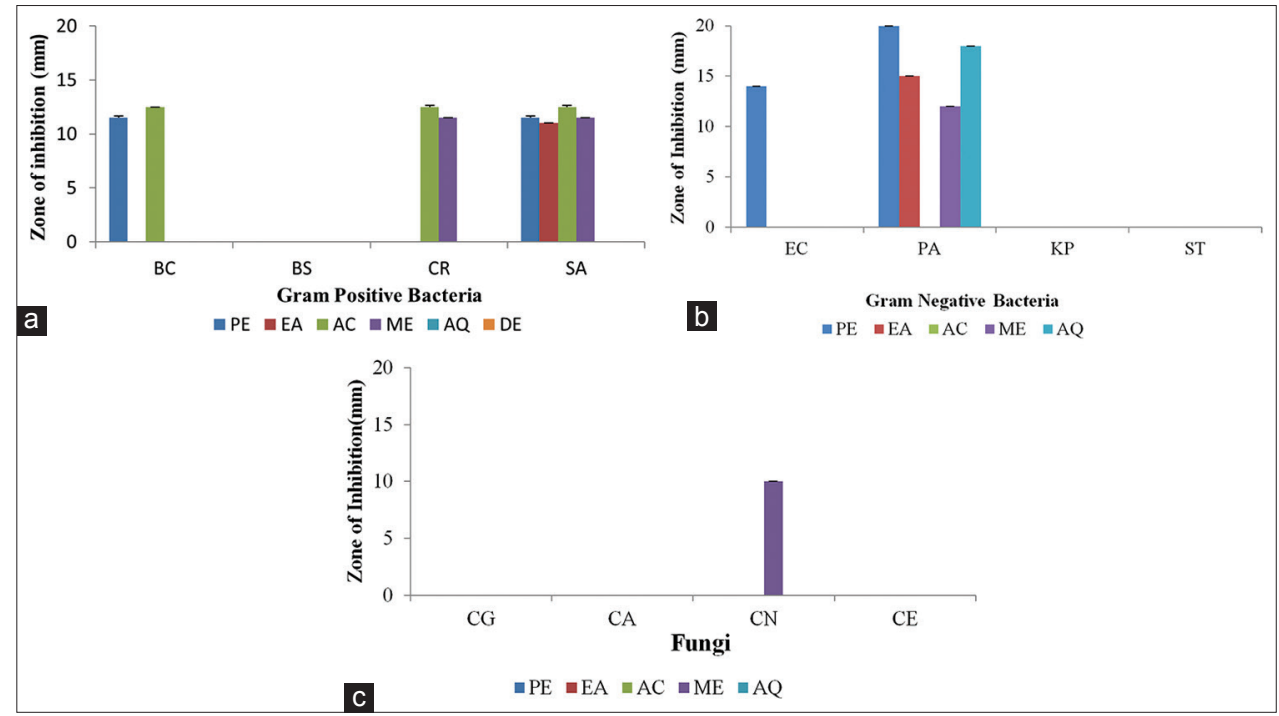

Fig. 6: Antimicrobial activity of different solvent extracts of $T$. angustifolia against (a) Gram-positive bacteria, (b) Gram-negative bacteria and (c) fungi 
and Gram-negative bacteria as compared to fungi. In Gram-positive bacteria, $S$. aureus was inhibited by non-polar solvent PE, semi polar solvent EA, polar solvent acetone, and methanol extracts. C. rubrum was inhibited by acetone and methanol extracts. B. cereus was inhibited by PE and acetone extracts. B. subtilis was the most resistant bacterial strain (Fig. 6a). In Gram-negative bacteria, P. aeruginosa was inhibited by five extracts expect acetone extract. $E$. coil was inhibited by nonpolar solvent PE extract. K. pneumoniae and $S$. typhimurium were the most resistant bacterial strain (Fig. 6b). Fungi, C. glabrata, C. albicans, and C. epicola were the most resistant fungal strains. C. neoformans was inhibited by polar solvent methanol extract (Fig. 6c). In general, polar solvent methanol extract showed maximum antimicrobial activity. $P$. aeruginosa and S. aureus were the most susceptible bacterial strains.

All the five plant solvent extracts showed a different level of antimicrobial activity against different microorganisms. Out of 5 plant extracts, $S$. nigra extracts show broad-spectrum antimicrobial activity. The antimicrobial activity of plant extracts could be due to various phytochemical constituents present in the respective crude extracts [21]. Qualitative phytochemical analysis revealed the presence of a different level of phytochemicals in different plants and they may be responsible for the observed different levels of antimicrobial activity of in all the solvent extracts of five plants [22].

All extracts of five plants showed better antibacterial activity than antifungal activity; Gram-positive bacteria were more susceptible than Gram-negative bacteria. The differences in antimicrobial activity could be attributed to the presences of an additional external membrane surrounding the cell wall in Gram-negative bacteria which blocks the easy penetration of the bioactive compounds [23,24]. Among different extracts of different plants, methanol and acetone extracts displayed better and broad antimicrobial activity; a clear effect of the polarity of the solvents was envisaged. Similar results are reported by Padalia and Chanda [25] in Tagetes erecta, Nouri et al., [26] in Piper betel, and Morales-Cabrera et al. [27] in Hibiscus sabdariffa.

\section{CONCLUSION}

All the five plants exhibited a broad spectrum of antimicrobial activity against a wide range of tested microorganism. The solvent extracts of S. nigra aerial part exhibited the best activity among the five different plants screened, and thus it can be considered as a good source of the natural antimicrobial agent against infectious disease causing microorganisms. This plant extracts can be further studied for their synergistic approach in treating the multidrug resistant microorganisms.

\section{ACKNOWLEDGMENTS}

The authors thank the Department of Biosciences (UGC-CAS) for providing excellent research facilities. One of the authors Hemali Padalia thank UGC-CAS, New Delhi, for providing Senior Research Fellowship.

\section{REFERENCES}

1. Rathod MC, Dhale DA. Pharmacognostic characterization and phytochemical screening of Launaea procumbens. Int J Pharm Res Sch 2013;3(1):41-50.

2. Mahesh B, Satish S. Antimicrobial activity of some important medicinal plant extract against plant and human pathogens. World J Agric Sci 2008;4(5):839-43.

3. Regis AS, Gabriel JJ. Antifungal activity of Cyanotis axillaris (L.) D. Don ex sweet against opportunistic fungal strains. Int J Pharm Pharm Sci 2017;9(7):140-3.

4. Kusmardiyani S, Novita G, Fidrianny I. Antioxidant activities from various extracts of different parts of kelakai (Stenochlaena palustris) grown in central Kalimantan - Indonesia. Asian J Pharm Clin Res 2016;9(2):215-9.

5. Lad H, Dixit D, Joshi A, Bhatnagar D. Antioxidant and antiinflammatory effects of Vitex negundo on freund's complete adjuvant induced arthritis. Int J Pharm Pharm Sci 2015;7(1):81-5.

6. Ahmad R, Raja V, Sharma M. Hepatoprotective activity of ethyl acetate extract of Adhatoda vasica in swiss albino rats. Int J Curr Res Rev 2013;5(6):16-21.

7. Khan MF, Khan ZI, Uddin RM, Rahman MS, Rashid MA. In vivo hypoglycemic and alloxan induced antidiabetic activity of Xeromphis uliginosa Retz. Afr J Pharm Pharmacol 2015;9(11):363-6.

8. Ghate NB, Hazra B, Sarkar R, Mandal N. In vitro anticancer activity of Spondias pinnata bark on human lung and breast carcinoma. Cytotechnology 2014;66(2):209-18.

9. Selvamohan T, Ramadas VS, Shibila SK. Antimicrobial activity of selected medicinal plants against some selected human pathogenic bacteria. Adv Appl Sci Res 2012;3(5):3374-81.

10. Dean DA, Burchard KW. Fungal infection in surgical patients. Am J Surg 1996;171(3):374-82.

11. Graybill JR. Histoplasmosis and AIDS. J Infect Dis 1988;158(3):623-6.

12. Sieradzki K, Roberts RB, Haber SW, Tomasz A. The development of vancomycin resistance in a patient with methicillin-resistant Staphylococcus aureus infection. N Engl J Med 1999;340(7):517-23.

13. Amer WM, Abouwarda AM, El Garf IA, Dawoud GT, Abdelmohsen G. Phytochemical composition of Solanum elaeagnifolium Cav. and its antibacterial activity. J Biol Pharm Appl Sci 2013;2(6):1282-306.

14. Parekh J, Chanda S. In vitro antibacterial activity of the crude methanol extract of Woodfordia fructicosa kurz. flower (Lythraceae). Braz J Microbiol 2007;38:204-7.

15. Perez C, Paul M, Bazerque P. An antibiotic assay by the agar well diffusion method. Acta Biol Med Exp 1993;15:113-5.

16. Chanda S, Rakholiya K, Parekh J. Antimicrobial efficacy of Mesua ferrea $\mathrm{L}$. seed extracted in different solvents against infection causing pathogenic strains. J Acute Dis 2013;2(4):277-81.

17. Fernández-Agullo A, Pereira E, Freire MS, Valentao P, Andradec PB, Gonzalez-Alvareza J, et al. Influence of solvent on the antioxidant and antimicrobial properties of walnut (Juglans regia L.) green husk extracts. Ind Crops Prod 2013;42:126-32.

18. Chanda S, Parekh J, Baravalia Y, Parekh S. Antimicrobail and antioxidant efficacy of various solvent extracts of seeds and fruits rind of Caesaipinia pulcherrima Swartz. Arch Clin Microbiol 2010;1:1-7.

19. Al-Farsi M, Lee CY. Optimization of phenolics and dietary fibre extraction from date seeds. Food Chem 2008;108(3):977-85.

20. Ammar I, Ennouria M, Atti H. Phenolic content and antioxidant activity of cactus (Opuntiaficus-indica L.) flowers are modified according to the extraction method. Ind Crops Prod 2015;64:97-104.

21. Kumar GD, Tulasi CD, Ramakrishnaiah G. Phytochemical screening and evaluation of in vitro antimicrobial activity of Drosera spatulata Var. Bakoensis-an indigenous carnivorous plant against respiratory tract infectious microbes. Asian J Pharm Clin Res 2016;9(6):274-83.

22. Padalia H, Chanda S. Comparative phytochemical analysis of aerial parts of A. procumbeans, F. dichotoma, S. sponteneum, S. nigra and T. angustifolia. J Phcog Phytochem 2015;4(2):11-6.

23. Burt S. Essential oils: Their antibacterial properties and potential applications in foods-a review. Int J Food Microbiol 2004;94(3):223-53.

24. Kavak DD, Altiok E, Bayraktar O, Ulku S. Pistacia terebinthus extract: As a potential antioxidant, antimicrobial, and possible [3-glucuronidase] inhibitor. J Mol Catal B Enzym 2010;64(3):167-1.

25. Padalia H, Chanda S. Antimicrobial efficacy of different solvent extracts of Tagetes erecta L. flower, alone and in combination with antibiotics. Appl Microbiol 2015;1(1):1-10.

26. Nouri L, Nafchi AM, Karim AA. Phytochemical, antioxidant, antibacterial, and amylase inhibitory properties of different extracts from betel leaves. Ind Crops Prod 2014;62:47-52.

27. Morales-Cabrera M, Hernández-Morales J, Leyva-Rúelas G, SalinasMoreno Y, Soto-Rojas L, Castro-Rosas J. Influence of variety and extraction solvent on antibacterial activity of Roselle (Hibiscus sabdariffa L.) calyxes. J Med Plants Res 2013;7(31):2319-2. 